\title{
Performance Analysis of Indoor Positioning System
}

\author{
Leena Arya \\ Research Scholar \\ Electronics \& Computer \\ Engg. Discipline \\ DPT, IIT Roorkee \\ leenadpt@iitr.ernet.in
}

\author{
S.C. Sharma \\ Associate Professor \\ Electronics \& Computer \\ Engg. Discipline \\ DPT, IIT Roorkee \\ scs60fpt@iitr.ernet.in
}

\author{
Millie Pant \\ Assistant Professor \\ Mathematics Discipline \\ DPT, IIT Roorkee \\ millifpt@iitr.ernet.in
}

\begin{abstract}
In the new era of wireless communication, Wireless Local Area Network has emerged as one of the key players in the wireless communication family. It is now a trend to develop the WLAN in various colleges and office campuses for increasing productivity and quality of goods. There are many obstacles when deploying WLAN, which demands seamless indoor handover. The objective of the work reported here is to develop modeling tools using QUALNET 5.0 simulation design tool for performance optimization of WLAN access points. To predict the signal strength and interference in a WLAN system, propagation model has been used.
\end{abstract} 5.0.

Keywords-WLAN, Access point, Path loss model, Qualnet

\section{INTRODUCTION}

The popularity of IEEE 802.11 based wireless LAN has increased substantially in recent years. WLAN networks have become very popular means for providing a wireless networking facility for home users, educational institutions, companies etc. due to their ease of installation and their high data rate provision, apart from providing, although limited, mobility to users. Most of today's WLAN systems operate in the unlicensed 2.4 $\mathrm{GHz}$ band and follow the IEEE 802.11b standard, which is a wireless extension of the Ethernet standard and allows data rates up to $11 \mathrm{Mbps}$ [2].

If the APs are placed too far apart, they will generate a coverage gap, but if they are too close to each other, this will lead to excessive co-channel interferences and increases the cost unnecessary. In this paper, we present methods to determine location in such a WLAN. For the indoor environment, there are two types of elements; namely static and dynamic elements. The static elements are such as natural and manmade materials. The dynamic element comprises of moving objects [3]. In an indoor environment, additional parameters must be considered, such as reflection, wall penetration, how fast the channel changes and etc.

The capability of QUALNET to simulate this indoor environment scenario close to the real situation condition motivates us to employ this software to further the study on RF indoor characteristics.
This paper is organized as follows: Section II presents the indoor path loss. Notations are given in section III. Section IV presents the mathematical model description and path loss model. Section V shows the algorithm of the access point's calculation. Section VI shows the comparison of various models. Section VII describes the method of testing. Section VIII shows the results. Finally, section IX gives the conclusion.

\section{INDOOR PATH LOSS}

Path Loss or attenuation of RF signals occurs naturally with distance. Obstacles between the transmitter and receiver also attenuate signals. The amount of attenuation varies with the frequency of the RF signal and the obstructing materials type and density [6]. Generally speaking, the lower the frequency of transmission the better the signal will travel through the air and through objects as shown in figure-1.

Indoor propagation mechanism needs to overcome three specific main electromagnetic wave phenomena, namely the reflection, diffraction and scattering. These phenomena may occur and degrade the signal strength quality of the WLAN network. The distance between transmitter and receiver is shorter due to high attenuation caused by the internal walls \& furniture and often also because of the lower transmitter power. The short distance implies shorter delay of echoes and consequently a lower delay spread.

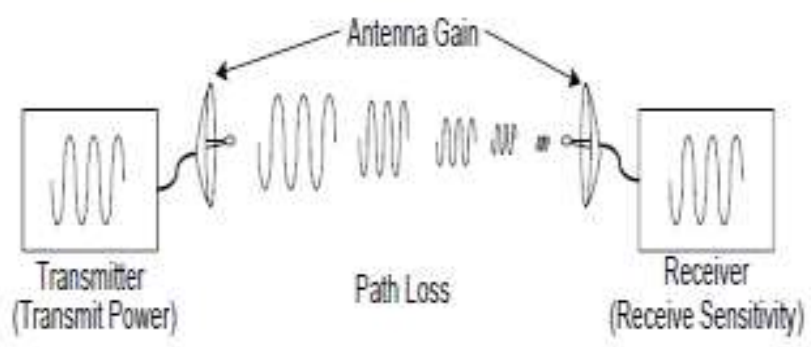

Figure 1 .Indoor path loss 


\section{GENERAL NOTATIONS} used:

Throughout this paper the following notations are

$\begin{array}{ll}a_{j} & j=1 \ldots N \quad \text { Access point (AP) } \\ r_{i} & i=1 \ldots M \quad \text { Receiver/user } \\ d\left(a_{j}, r_{i}\right) & \text { Distance between AP and receiver } \\ g\left(a_{j}, r_{i}\right) & \text { Path loss from } i_{t h} \text { user to access } \\ & \text { point j } \\ g \text { max } & \text { Maximum tolerable path loss } \\ P_{t} & \text { Transmit power } \\ \mathrm{Pr}_{\mathrm{r}} & \text { Received power } \\ R_{t h} & \text { Receive threshold } \\ A p & \text { Position of AP }\end{array}$

It should be noted that $a_{j}$ represents the unknown coordinates of APs. Their number $\mathrm{N}$ is not known either. The coordinates of users $r_{i}$ are assumed to be known and these users can be distributed in design area according to the design specifications.

In the present analysis the distance function assumed to be Euclidean, hence on the plane, the distance $(d)$ between an AP $a_{j}$ and a receiver $r_{i}$ is given by [4]:

$$
\begin{gathered}
d\left(a_{j}, r_{i}\right)=\sqrt{\left(r_{i}{ }^{1}-a_{j}{ }^{1}\right)^{2}+\left(r_{i}{ }^{2}-a_{j}{ }^{2}\right)^{2}} \\
\text { where } a_{j}=a_{j}\left(a_{j}{ }^{1}, a_{j}{ }^{2}\right) \text {, and } r_{i}=r_{i}\left(r_{i}{ }^{1}, r_{i}{ }^{2}\right)
\end{gathered}
$$

\section{MODEL DESCRIPTION}

The aforementioned problem can be modeled as an optimization problem for which the objective function is to minimize the path loss. Mathematically it may be given as:

$$
\min g\left(a_{j}, r_{i}\right) \leq g \max \forall i=1, \ldots, M
$$

Constraint (1) states that path loss is evaluated against the maximum tolerable path loss $g$ max. This ensures that the quality of coverage at each receiver location is above the given threshold.

This given value, $g$ max can be calculated by subtracting receiver threshold $\left(R_{t h}\right)$ from transmitter power $\left(P_{t}\right)$.

$$
g \max =P_{t}-R_{t h}
$$

The above inequality (1) can be expressed in the equality form as:

$$
\begin{array}{r}
\left(\min _{j} g\left(a_{j}, r_{i}\right)-g \max \right)^{+}=0, \\
\text { Where }(\alpha)^{+}=\max (\alpha, 0)
\end{array}
$$

\section{A. Path Loss Model}

In general the power received by an antenna that is separated from the transmitting antenna by the distance $d$ in free space is given by [4-5]:

$$
\operatorname{Pr}\left(a_{j}, r_{i}\right)=\frac{P_{t} G_{t} G_{r} \lambda^{2}}{(4 \pi)^{2} d\left(a_{j}, r_{i}\right)^{2}}
$$

where $P_{t}$ is the transmitted power, $G_{t}$ and $G_{r}$ are the transmitter and receiver antenna gain, $d$ is the distance between transmitter and receiver, and $\lambda=c / f$ is the wavelength of the carrier frequency, $c$ is the speed of light $\left(3 \times 10^{8}\right.$ meter per second $)$ and $f$ is the frequency of radio carrier in hertz. The path loss, which represents signal attenuation between the transmitted and the received power and is measured in $\mathrm{dB}$ (decibels), in free space environments, is given by [45]:

$$
g\left(a_{j}, r_{i}\right)[d B]=-10 \log \left[\frac{G t G r \lambda^{2}}{(4 \pi)^{2} d\left(a_{j}, r_{i}\right)^{2}}\right]
$$

The above equation does not hold when points $a_{j}$ and $r_{i}$ are very close to each other. Therefore, large scale propagation models use a close-in distance, $d_{0}$ which is known as the received power reference distance point. Therefore, path losses at reference distance assuming transmit and receive antenna with unity gain as described in [4-5] can be calculated from:

$$
g\left(a_{j}, r_{i}\right)=g\left(d_{o}\right)[d B]=20 \log \frac{4 \pi d_{o} f}{c}
$$

Therefore, path loss function in free space at a distance greater than $d_{0}$ is given by

$$
\begin{gathered}
g\left(a_{j}, r_{i}\right)[d B]=g\left(d_{o}\right)[d B]+10 \log \left(\frac{d\left(a_{j}, r_{i}\right)}{d_{o}}\right)^{2} \\
\text { V. COMPUTATIONAL STEPS FOR ACCESS } \\
\text { POINT'S CALCULATION }
\end{gathered}
$$

Initially set the number of APs to $1: \mathrm{N}=1$; then the necessary number of APs is found through the following steps.

1) Solve the constraint condition of path loss for each receiver using equation (3);

2) Solve the power received by an antenna in free space using equation (4); 
3) If the solution exists, then $N$ is the desired number;

4) Otherwise, $N$ is increased by 1: $N=N+1$;

5) Go to step 1.

\section{COMPARISON OF VARIOUS MODELS}

Mari Kobayashi, et.al [1] has applied a nonlinear optimization scheme called very fast simulated annealing to search for an approximate optimal solution using orthogonal frequency division multiplexing (OFDM) for high data rate indoor wireless LAN.

Max Kamenetsky, et.al [2] has described the methods for obtaining a close-to-optimal positioning of WLAN APs and evaluates their performance in a typical downtown or campus environment using pruning for obtaining an initial set of transmitter positions and refining these by using either neighborhood search or simulated annealing.

Mohd. Dani Baba, et. al [3] has developed a mathematical path loss model using OPNET 10 simulation design tool, to evaluate the performance of indoor WLAN mobility.

S. Kouhbor, et. al [4] has described a mathematical model developed to find the optimal number and location of APs. To solve the problem, he used the Discrete Gradient optimization.

S. Kouhbor, et. al [5] has described the mathematical model that finds the minimum number of APs for indoor buildings and places them in the area in a manner that the physical security of the network is maintained.

Table I. shows the comparison of various models.

\section{METHOD OF TESTING}

\section{A. Setup}

A simple case without obstacles was considered for conducting the test in order to examine the model. The design area has 40 users. The specification of the model

TABLE.I COMPARISON OF VARIOUS MODELS

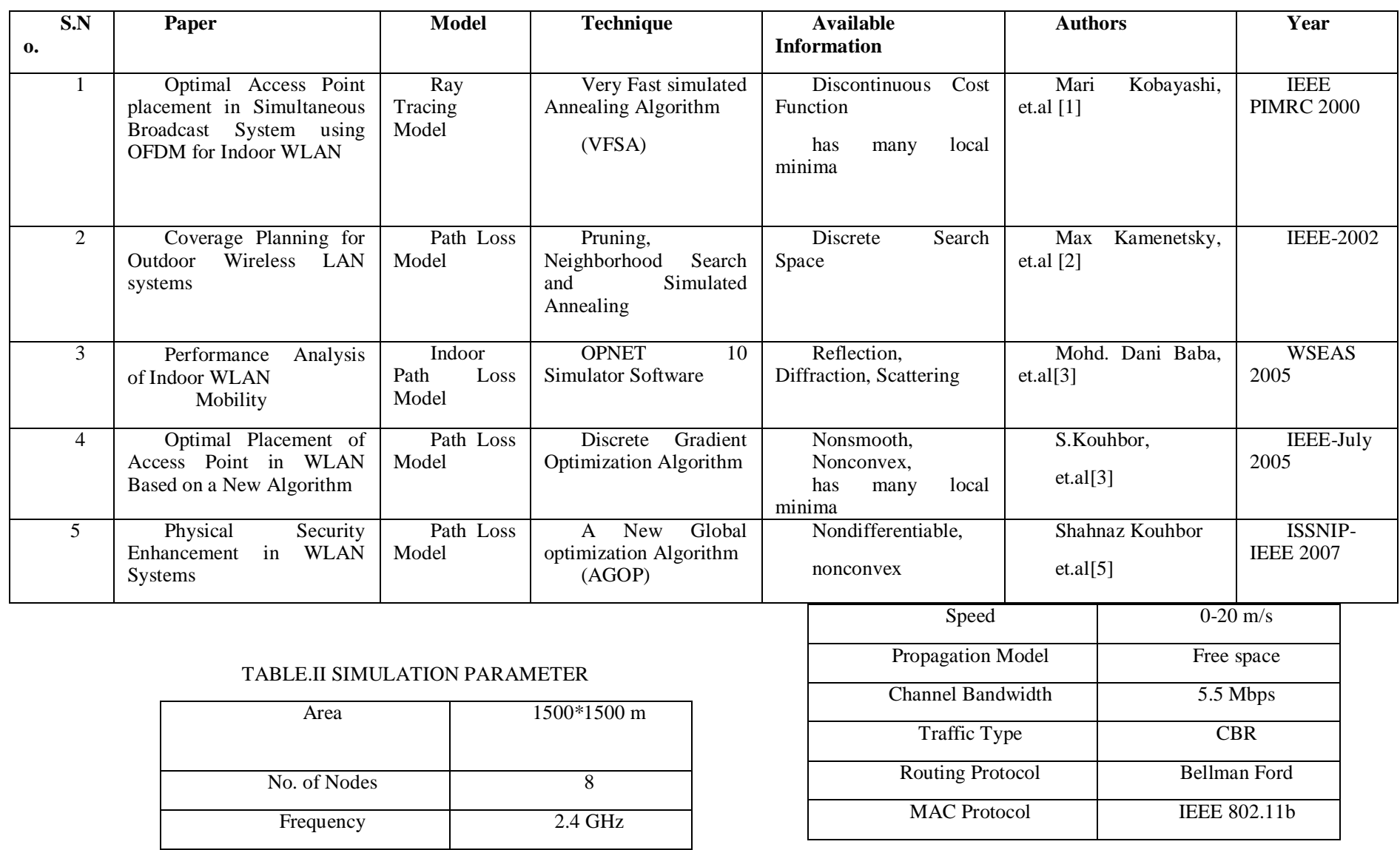

of Access point is LINK (DWL-3200AP) and IEEE $802.11 \mathrm{~b}$ standard are used to test the model. 
We conducted our experiments at the ground floor of the Boys Hostel Building in IIT Roorkee, Saharanpur Campus. Eight Access Points were installed in the ground floor of the building and these were configured to use channels since these eight channels are non overlapping. Our data collection system comprised of a laptop, running Windows 2007. Table II. Shows the simulation parameters.

\section{B. Methodology}

Once the priority areas have been identified, look for places nearby where it will be easy to install an access point. Access point will require a connection to the wired LAN and also a source of power. The signal strength, noise level and signal/noise ratio should then be measured, using $3.3 \mathrm{GHz}$ Spectrum analyzer with Omni directional dipole antennas has been chosen, at a number of points around the access point. The coverage should be checked in those priority areas that are within range. While in other places the aim should be to identify the points where the available bandwidth is likely to drop below the theoretical maximum: typically where the signal strength falls below $-70 \mathrm{dBm}$ or where the signal/noise ratio is less than about $15 \mathrm{~dB}$ [7].

\section{RESULTS}

\section{A. Case I}

Fig. 2 shows that the mobile node moves from one to another access point using Qualnet 5.0 simulation software. It should be noted that in the developed model, the aim is to provide only the coverage for the users. Figure. 2 shows a part of the Boy's Hostel Map. In this figure the access points covering the whole region.

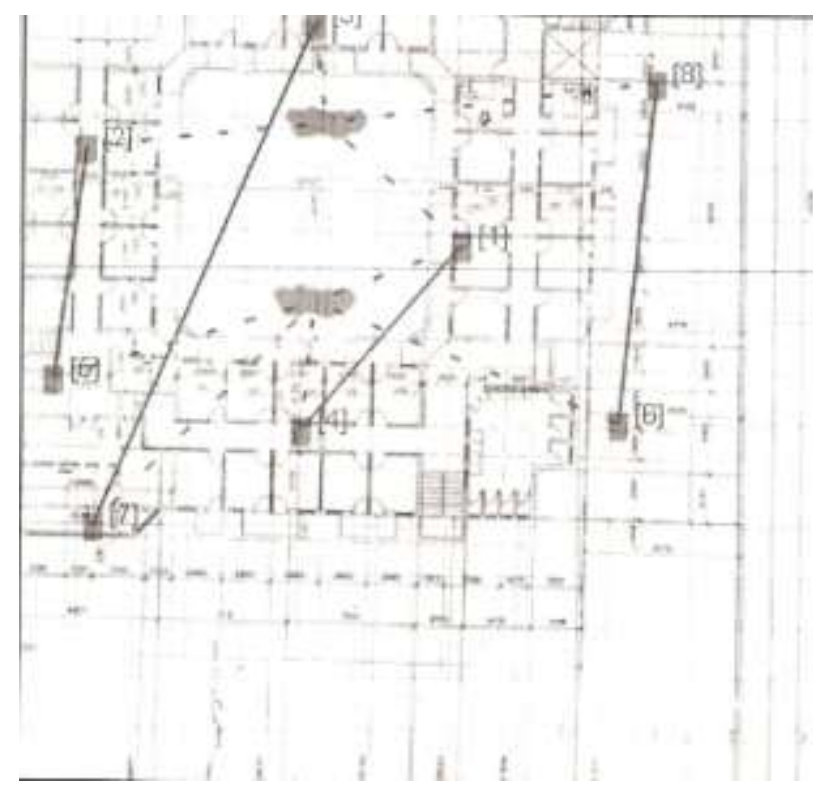

Figure. 2 shows Mobility in the part of the Boy's Hostel Map

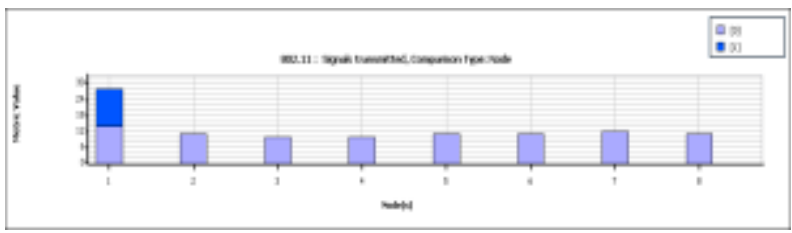

Figure. 3 shows the signals transmitted

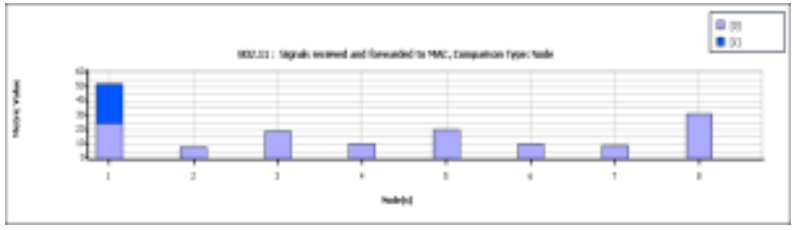

Figure. 4 shows the signals received

Figure. 4 shows the signals received so that we can assure the coverage of all users.

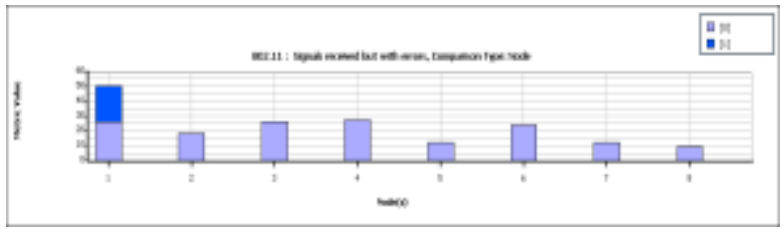

Figure. 5 shows the signals received but with errors

Figure. 5 shows the signals received but with errors so that we can calculate the path loss in free space.

Figure.3, Figure.4 and Figure.5 show that results have been achieved for indoor path loss model for WLAN coverage.

Drawing a line through these points will create a rough contour map of the wireless coverage. The access point should then be moved to the next priority area that was not properly covered from the first position and the process repeated until all the required areas have been covered.

\section{CONCLUSION}

By using this simulation program, WLAN planner will be able to setup the access point for the optimum propagation coverage. Further work will be extended to include obstacles in the mathematical model presented in this paper and test will be conducted and also it will involve the comparison of results taken by the optimization technique and by the simulation software.

\section{ACKNOWLEDGMENT}

I would like to thanks the Ministry of Science, department of Science and Technology, New Delhi for sponsoring this work under Women Scientist Scheme WOS-A, Grant No: DST-498-DPT.

\section{REEFERENCES}

[1] M.Kobayashi, S.Haruyama, R.Kohno, M.Nakagawa, "Optimal Access Point Placement in simultaneous broadcast system using 
OFDM for indoor wireless LAN", IEEE symposium on PIMRC, Vol.1, PP.200-204, 2000.

[2] M. Kamenetsky and M. Unbehaun, "Coverage Planning for outdoor

Wireless LAN Systems," in Proc. IEEE International Zurich

Seminar on Broadband Communications, Sweden, pp.49-1

- 49-6, 2002.

[3] Mohd. Dani Baba, Mohammad Ibrahim, Bdulmukti Ahmad, "Performance Analysis of Indoor WLAN Mobility", Proceedings of the 4th WSEAS International Conference on Electronics,Hardware,

Wireless and Optical, 2005.

[4] S. Kouhbor, J.Ugon, A. Kruger, A.Rubinov, "Optimal Placement of Access Point in WLAN Based on a New Algorithm", In: proc. Of the International Conference onMobile Business-IEEE/ICMB, pp. 592-598, July 2005.

[5] Shahnaz Kouhbor, "Physical Security Enhancement in WLAN Systems", ISSNIP-IEEE, pp.733-738, 2007.

[6] AvaLAN Wireless Systems Inc., 1020 Corporation Way,Palo Alto, CA 94303, August 2006.

www.avalanwireless.com/assets_ $v 3 / . . . /$

[7] "Surveying Wireless Networks", GD/JANET/TECH, 2008. www.ukema.ac.uk/documents/.../technical../

\section{Authors Profile}

Leena Arya (leenadpt@iitr.ernet.in) received B.E. (Electronics and Communication Engg.) and M.E. (Electronics and Telecommunication Engg.) in the year 2001 and 2007 respectively. She started her career in teaching profession as a Lecturer in Lingaya's institute of mgmt and technology, Faridabad then she worked in Dehradun institute of Technology, Dehradun. She has got the best research paper award, prize and medal for the paper in the International Conference. She is the honorary member of IAENG and ISOC. Presently she is pursuing Ph.D. at I.I.T., Roorkee in the field of Analysis \& Optimization of QoS Parameter in Communication Network using an Evolutionary Algorithms Approach.

Dr. S.C. Sharma (scs60fpt@iitr.ernet.in) received M.Tech (Electronics \& Communication Engg. and Ph.D. (Electronics \& Computer Engg.) in 1983 and 1992 respectively from IIT Roorkee (erstwhile University of Roorkee). He started his career as R \& D Engineer in 1983 then joined teaching profession in Jan. 1984 in IIT-Roorkee and continuing till date. He has published over one hundred fifty six research papers in national and international journals/conferences and supervised more than 30 projects/dissertation of PG students. He has supervised several Ph.D. in the area of Computer Networking, Wireless Network, Computer Communication and continuing supervising Ph.D. in the same area. Currently, he is supervising seven Ph.D. Scholars. He has successfully completed several major research projects independently and many minor research projects related to Communication and SAW filter Design sponsored by Government of India. IIT-Roorkee has awarded him the Khosla annual research prize with best research paper in the year 2000 . His many research papers have been awarded by National and International Committees. He has worked as research scientist at FMH, Munchen, Germany in the year 1999. $\mathrm{He}$ has chaired several national and International Conferences. $\mathrm{He}$ is the active reviewer of IEEE Sensor Journal and Chief Editor of various reputed International Journals and Editor of National Journal (BITS, PILANI). He is the honorary member of NSBE, ISOC, and IAENG, USA. He has also worked as Group leader of Electronics \& Instrumentation Engg. Department of BITS-Pilani-Dubai Campus, from Aug. 2003 to Aug. 2005. Presently he is continuing as Associate Professor at IIT Roorkee.

Millie Pant (millifpt@iitr.ernet.in) is working as an assistant professor in the department of paper technology, IIT Roorkee since 2007. Her areas of interests are global optimization, evolutionary techniques and swarm intelligence. She has more than 50 publications in journals and conference proceedings of national and international repute. She is a reviewer of several journals like IEEE transactions of Evolutionary Computation, Soft computing etc. At present there are 6 research scholars working with her. 